\title{
Развитие концепции правовой системы в зарубежной правовой доктрине второй половины XX - начала XXI века
}

\author{
Гаврилов В.B.
}

Единодушно признавая необходимость использования категории "правовая система» в научных исследованиях и правотворчестве, ученые-юристы до сих пор не могут прийти к единому мнению относительно содержания данного термина. Представления об этой проблеме даже на внутригосударственном уровне, не говоря уже об уровне международно-правовом, существуют самые различные. Достаточно сказать, что в некоторых трудах российских авторов правовая система до сих пор отождествляется с понятием «система права»', которое в действительности относится лишь к внутренней структуре позитивного права, его подразделению на отрасли и правовые институты.

К сожалению, объем настоящего исследования не позволяег детально остановиться на анализе точек зрения и аргументации сторонников различных подходов к пониманию содержания термина «правовая система», существующих в отечественной доктрине права. Это нецелесообразно еще и потому, что автором данной статьи уже излагались в печати определенные соображения на этот счет ${ }^{2}$. Поэтому целью статьи является ознакомление читателя лишь с наиболее авторитетными зарубежными точками зрения по этому поводу. Соответствующая информация, на наш взгляд, будет способствовать формированию в рос-

- Гаврилов Вячеслав Вячеславович - к.ю.н., доцент, заведующий кафедрой международного права, декан международно-правового факультета Дальневосточного госуниверситета.

${ }^{\prime}$ См., например: Каланда $B . A$. О трансформации норм международного права в правовую систему РФ (конституционно-правовой анализ) // Московский журнал международного права. 1994. № 3. С. 23; Усенко E.T. Соотношение и взаимодействие международного и национального права и российская Конституция // Московский журнал международного права. 1995. № 2. С. 18; Теория государства и права: Учебник для вузов / Под ред. Г.Н. Манова. М., 1995. С. 180-183; Теория государства и права: Учебник / Под ред. проф. В.В. Лазарева. 2-е изд., перераб. и доп. М., 2002. С. 211-212. ${ }^{2}$ См.и: Гаврилов В.В. Развитие концепции правовой системы в отечественной доктрине права: общетеоретический и международно-правовой подходы // Журнал российского права. 2004. № 1. С. 76-87. 
сийских научных кругах более широкого представления о существе рассматриваемой проблемы, а также выработке единого представления о содержании указанной юридической категории, что особенно важно в контексте правильного понимания и применения ч. 4 ст. 15 Конституции России.

Термин «правовая система» получил широкое распространение как в отечественной, так и в зарубежной правовой доктрине во второй половине прошлого века. Именно в это время в трудах по общей теории права все чаще стала проводиться мысль о том, что правовую действительность «трудно отображать с помощью слишком узких конструкций. Требуются более широкие построения (комплексы), позволяющие производить соответственно и более гибкие и адекватные научные операции, достигать более высоких уровней обобщения, абстракции» ${ }^{3}$. Д.А. Керимов, например, определяя теоретико-познавательные корни введения в научный оборот понятия правовой системы, указывал, что «на смену относительно изолированному, дифференцированному изучению отдельных звеньев правовой системы приходит интегрированное ее осмысление на высшем уровне» ${ }^{4}$.

Схожей точки зрения придерживались и зарубежные исследователи. Так, в частности, американский исследователь Л. Фридмэн в своей часто цитируемой российскими учеными книге «Введение в американское право» утверждал, что правовая система государства состоит из следуюших трех основных компонентов: 1) «структуры», в которую включаются принципы правовой системы и правовые учреждения; 2) «сущности», которая объединяет нормы и образцы поведения людей внутри правовой системы; 3) «правовой культуры», под которой понимаются отношение людей к праву, их ожидания и идеалы в правовой сфере жизни общества 5 .

Изучению национальных правовых систем посвятил свое знаменитое исследование французский ученый Р. Давид. «Было бы поверхностным и неправильным, - писал он, - видеть в праве только лишь совокупность норм. ....Право - это значительно более сложное явление, выступающее как система. У нее определенный понятийный фонд; она соединяет нормы в определенные группы; использует определенные

\footnotetext{
${ }^{3}$ Теория государства и права: Курс лекций / Под ред. Н.И. Матузова и А.B. Малько. 2-е изд., перераб. и доп. М., 2002. С. 178.

${ }^{4}$ Керимов Д.А. Философские проблемы права. М., 1973. С. 270.

${ }^{5}$ См.: Теория государства и права: Учебник / Под ред. М.Н. Марченко. 3-е изд., расширенное и доп. М., 2001. С. 437.
} 
способы создания и толкования норм: она связана с определенной концепцией социального строя, и от этой концепции зависит, как применяется и вообще функционирует право» ${ }^{6}$.

Немецкие профессора К. Цвайгерт и X. Кётц отмечали, что при изучении национальных правовых систем можно использовать как широкий, так и узкий подход. В первом случае речь идет об исследовании «духа и стиля» права конкретных стран, методов его понимания и процедур осуществления, во втором - о сопоставлении специфических юридических институтов и проблем, а также правовых норм, используемых для разрешения общих вопросов и частных конфликтов интеpecos ${ }^{7}$.

Здесь необходимо отметить, что с обоснованием «узкого» понимания концепции правовой системы выступал еще один из основоположников нормативизма Г. Кельзен. В рамках разработанной им «чистой теории права» Г. Кельзен отстаивал идею о том, что право абсолютно автономно и самодостаточно и его действительность определяется исключительно юридическими нормами, а не нравственными принципами или какими-то иными внешними системами ценностей. Г. Кельзен отмечал, что право имеет дело не с фактами человеческого поведения, а с нормами, которые являются образцами поведения и составляют часть однородной правовой системы. Последняя представляет собой определенную иерархию норм, располагающихся на разных уровнях универсальности и субординации. По мнению Г. Кельзена, в любой правовой системе должна существовать точка, за которую нельзя выходить, поскольку она служит внешней границей всей системы, и дальнейшее продвижение будет уже означать анализ, не имеющий к этой системе никакого отношения 8 .

Международное и внутригосударственное право Г. Кельзен рассматривал в качестве составных частей указанной единой правовой системы и считал, что ее юридическая сила и содержание вытекают из базовой нормы следующего содержания: «Государства должны вести себя так, как они обычно себя вели» 9 . При этом Г. Кельзен подчеркивал, что международное право является высшим правопорядком, имеет

${ }^{6}$ Давид P., Жоффре-Спинози $K$. Основные правовые системы современности: Пер. с фр. В.А. Туманова. М., 1999. С. 19.

${ }^{7}$ Zweigert K., Kötz H. Introduction to Comparative Law. Oxford, 1993. P. 4-5.

${ }^{8}$ См.: Ллойд Д. Идея права: Пер. с англ. М.А. Юмашева, Ю.М. Юмашев. М., 2002. C. $220-222$.

${ }^{9}$ См.: Brownlie I. Principles of Public International Law. Fifth Edition. Oxford. 1998. P. 32-33. 
приоритет над правом внутригосударственным и что его действие, следовательно, «не может быть ограничено ни в каком направлении» ${ }^{10}$.

«Узкой» трактовки понятия национальной правовой системы в настоящее время придерживается, в частности, профессор Свободного университета Амстердама Э. Бланкенбург. Правда, в обоснование своей точки зрения он приводил совершенно другие, нежели у Г. Кельзена, аргументы. Э. Бланкенбург считал, что выражение «правовая система» следует применять только для описания характеристик формальных институтов и статутов позитивного права, в то время как для обозначения фактического применения права и доступа к нему следует использовать термин «правовая культура»"

Однако при всех различиях, существовавших между «узкой» и «широкой» трактовками понятия национальной правовой системы, их объединяло одинаковое отношение к внутригосударственному праву как к фундаменту, на базе которого возникают все правовые явления и конструкции, существующие в обществе. В то же время в зарубежной правовой доктрине второй половины прошлого века не существовало подобного единства взглядов по отношению к международному праву как к нормативной основе функционирования международной системы. Более того, в зарубежных концепциях международной системы во многих случаях отрицался сам факт сушествования международного права как совокупности юридических норм или существенно принижалась его роль в регулировании международных отношений.

Причину возникновения подобных точек зрения в зарубежной правовой доктрине следует искать, на наш взгляд, не только «в относительной неразвитости международного права в течение длительного периода времени по сравнению с национальными системами права» ${ }^{12}$, но и в специфическом характере самих международно-правовых норм по сравнению с нормами внутригосударственными, а также в особенностях той среды, в рамках которой международное право функционирует. Американские профессора М. Каплан и Н. Катценбах, одними из первых применившие в своих исследованиях метод системного анализа международного права, утверждали, например, в этой связи, что «международно-правовая система отличается от других систем от-

${ }^{10}$ Kelsen H. Principles of International Law. N.Y., 1967. P. 177.

"См.: Голландская правовая культура / Отв. ред. В.В. Бойцова и Л.В. Бойцова. М., 1998. C. 232.

${ }^{12}$ Марченко М.Н. Сравнительное правоведение. Общая часть: Учебник для юрид. ву3ов. М., 2001. С. 200. 
ношений между государствами своей «горизонтальной организацией», т.е. отсутствием иерархии в силу распределения власти между формально равнозначными элементами системы - суверенными государствами» ${ }^{13}$. Именно поэтому, как указывал Г. Еллинек, «возможность и существование международного права многократно подвергались сомнению» ${ }^{14}$.

Взгляды сторонников «минимизации» роли международного права в международной системе получили завершенное воплощение в теориях политического и юридического реализма, возникших в США во второй половине XX века. В свое время они были подвергнуты аргументированной критике российскими учеными ${ }^{15}$. Поэтому здесь вряд ли стоит еще раз обращаться к подробному анализу этого вопроса. Отметим лишь ключевые моменты этих теорий, для того чтобы иметь представление об их содержании и существе аргументации их сторонников.

Основы концепции «политического реализма» были заложены политологом и историком профессором Чикагского и Нью-Йоркского университетов Г. Моргентау. «Признание того факта, что международное право сушествует, - утверждал он, - не означает, однако, что оно представляет собой такую же эффективную правовую систему, как национальные правовые системы, и, в особенности, что оно является эффективным инструментом регулирования и сдерживания процесса борьбы за власть на международной арене... Международное право это примитивный тип права потому, прежде всего, что оно является почти полностью децентрализованным правом» ${ }^{16}$.

Децентрализованная природа международного права является, с точки зрения Г. Моргентау, неизбежным результатом децентрализованной структуры международного сообщества. «Национальное право устанавливается группой государственных чиновников, которые обладают монополией на организованную власть, - подчеркивал американский исследователь. - В то же время характерной чергой междуна-

${ }^{13}$ Блищенко И.П., Шавров В.Ф. Теория и пракгика международного права США: Учеб. пособие. М., 1985. С. 22-23.

${ }^{14}$ Цит. по: Марченко М.Н. Указ. соч. С. 200.

${ }^{15}$ См., например: Блищенко И.П., Шавров В.Ф. Указ. соч.; Курс международного права. В 7 т. Т. 1. С. 19-24; Мингазов Л.X. Проблема эффективности в зарубежной доктрине // Московский журнал международного права. 1998. № 2. С. 3-15; Тункин Г.И. Право и сила в международной системе. М., 1983. С. 86-112.

${ }^{16}$ Morgenthau H.J., Thompson K.W. Politics among Nations: The Struggle for Power and Peace. McGraw-Hill, Inc., 1985. P. 295. 
родного сообщества, состояшего из суверенных государств, ...является отсутствие централизованной власти, которая была бы способна заниматься правотворчеством и обеспечивать претворение в жизнь правовых норм. Вот почему существование и функционирование международного права определяют два фактора, каждый из которых носит децентрализованный характер: наличие общих интересов отдельных государств и распределение силы между ними. Где нет общности интересов и баланса силы, там нет и международного права» ${ }^{17}$.

Если Г. Моргентау и его последователи указывали на подчиненный и зависимый характер международного права в процессе регулирования международных отношений, то сторонники теории «юридического реализма», возникшей во времена холодной войны, отрицали сам факт его существования как системы обязательных юридических нормативных предписаний. Так, например, один из наиболее ярких представителей этой концепции профессор Йельского университета М. Макдугал утверждал, что международное право представляет собой совокупность «общественных предписаний», которые формируются, постоянно изменяются в «мировых процессах силы» путем предъявления государствами друг другу претензий и контрпретензий и эффективно применяются с помощью силы. Другими словами, в соответствии с теорией М. Мақдугала, «международное право, по существу, перестает быть особым компонентом международной системы системой обязательных норм, оно растворяется в политике» ${ }^{18}$.

Таким образом, как отмечал В.И. Евинтов, концепции политического и юридического реализма в зарубежной доктрине не признавали за международным сообществом «качество упорядоченного единства, основанного на координации и праве, на сотрудничестве и уважении суверенитета» ${ }^{19}$.

Скептическое отношение к международному праву, отличающее концепции Г. Моргентау и М. Макдугала, получило достаточно широкое распространение во второй половине XX века среди политологов, социологов и юристов. Одной из современных концепций, в рамках которой нашли развитие взгляды их последователей, стала теория «мирового менеджмента». Ее сторонники предлагают рассматривать тра-

\footnotetext{
${ }^{17}$ Morgenthau H.J., Thompson K.W. Op. cit. P. 295-296.

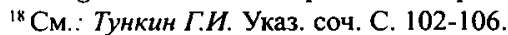

${ }^{19}$ Евинтов В.И. Международное сообщество и правопорядок (анализ современных концепций). Киев, 1990. С. 9.
} 
диционную область международного права в более широком контексте «режимов» мировой политики. Под такими режимами они понимают наборы явно выраженных и подразумевающихся принципов, норм, правил и процедур принятия решений, вокруг которых концентрируются ожидания участников конкретной области международных отношений. Совокупность этих режимов в различных сферах мировой политики и составляет, с их точки зрения, организм «мирового менеджмента», который выступает в качестве основного регулирующего начала современных мировых процессов ${ }^{20}$.

Тем не менее было бы неправильным полагать, что западная международно-правовая доктрина второй половины XX века находилась под доминируюшим влиянием реалистических школ. В этот же период в ее рамках развивался целый ряд теорий более либерального толка. Так, например, профессор Колумбийского университета О. Шахтер, отмечая то огромное влияние, которое сила оказывает на отношения между государствами и на формирование международно-правовых норм, признавал, тем не менее, существование целостного международного сообщества и подчеркивал, что «государства, сильные и не столь сильные, в целом соблюдают международное право». В свою очередь основатель «теории законности» Т. Френк указывал, что в современном мире организованное международное сообщество зиждется на праве и воле государств признавать законными нормы, институты и поведение отдельных стран. Причем, по его мнению, на это признание оказывают влияние такие факторы, как определенность и четкость норм и процедур, процессуальные формы придания действительности нормам, устойчивость их применения, признание нормативной иерархии права сообщества ${ }^{21}$.

Большое развитие в зарубежной международно-правовой доктрине получила институциональная теория, сторонники которой, как и «реалисты», считали, что первичными и определяющими отношениями на международной арене являются отношения между государствами. Однако в отличие от «реалистов» они полагали, что эффективное сотрудничество государств в рамках международного сообшества возможно и что значительную помощь в таком сотрудничестве государствам призваны оказывать международные институционные структу-

\footnotetext{
${ }^{20} \mathrm{Cм.:} \mathrm{Современные} \mathrm{международные} \mathrm{отношения:} \mathrm{Учебник} \mathrm{/} \mathrm{Под} \mathrm{ред.} \mathrm{A.B.} \mathrm{Торкунова.}$ M., 2000. C. 71-72.

${ }^{21}$ См.: Eвинтов В.И. Указ. соч. С. 11-12.
} 
ры. Так, например, один из видных представителей институциональной школы профессор М. Виралли считал, что международное сообшество должно рассматриваться через призму проблем функционирования универсальной международной организации, которая является ядром и основой развития этого сообщества. Сотрудничество государств в рамках подобной организации рассматривалось М. Виралли в качестве средства «сохранения основополагающей структуры международного сообщества, разделенного на суверенные государства» ${ }^{22}$.

Освещая основные положения теории институционализма, нельзя не вспомнить план реконструкции Устава ООН и создания на основе этой организации мирового правительства, предложенный в 60-е годы XX века американскими учеными Г. Кларком и Л. Соном в монографии «Всеобщий мир через мировое право» ${ }^{23}$. Они, в частности, предлагали превратить Генеральную Ассамблею $\mathrm{OOH}$ в своеобразный мировой парламент с правотворческими функциями, образовать единый мировой бюджет, создать полицейские силы мира «для соблюдения права и порядка в зрелом обществе или в государстве».

Однако уже тогда идея создания на основе перестройки ООН «мировой федерации» или «мирового правительства» вызвала серьезные возражения. Известный английский юрист В. Дженкс, например, признавая, что «обшая тенденция мирового развития проявляется и неизменно будет проявляться в движении от децентрализованного к институционализированному обществу, от мира государств к мировому сообществу», тем не менее подчеркивал, что «любая попытка чрезмерно упростить или чрезмерно централизовать структуру международного сообщества неизбежно подорвет его жизнеспособность» ${ }^{24}$.

Даже спустя несколько десятилетий после опубликования книги Г. Кларка и Л. Сона такой активный сторонник создания единого мирового сообщества государств, как Р. Фолк, был вынужден констатировать: «Потребность в новом мировом порядке имеется, однако на современном уровне социального и культурного развития было бы непрактично и нежелательно, чтобы этот порядок приобрел форму мирового правительства) ${ }^{25}$.

\footnotetext{
${ }^{22}$ См.: Virally M. L'Organisation mondiale. Paris, 1972. P. 279.

${ }^{23}$ CM.: Clark G. Sohn L. World Peace through World Law. Cambridge, 1958.

${ }^{24}$ Jenks W.C. New World of Law. London, 1969. P. 137, 266.

${ }^{25}$ Falk R. The Promise of World Order: Essays in Normative International Relations. Brighton, 1987. P. 15.
} 
Если «реалисты» и «институционалисты», исследуя структуру международной системы, исходили из того, что ее основными акторами являются государства, то близкий по взглядам к Г. Моргентау и М. Макдугалу в отношении роли силы в международных отношениях французский социолог Р. Арон различал понятие международной системы, как системы межгосударственных отношений и понятие международного сообщества, которое, по его мнению, охватывает международные немежгосударственные отношения. Р. Арон подчеркивал тесную связь между этими понятиями, отмечая, что государства заключают международные договоры, которые могут касаться как международного сообщества, так и международной системы. В свою очередь его коллега профессор М. Мерль считал, что понятие «международная система» должно включать как публичные, так и частные отношения, выходящие за пределы национальных границ, и объединять все человеческое сообщество ${ }^{26}$.

Сторонники «либеральной теории», получившей наибольшее распространение в 90-х годах прошлого века в Европе, также отмечали, что ключевыми субъектами в системе международных отношений являются не государства, а индивиды и частные группы. С их точки зрения приверженность государств предписаниям международного права определяется прежде всего степенью их «либеральности». Поэтому чем выше уровень защиты прав частных лиц в том или ином государстве, чем демократичнее характер регулирования отношений, возникающих с участием этих субъектов, тем более законопослушным в международно-правовом плане будет такое государство ${ }^{27}$.

Из тезиса, обосновываюшего необходимость включения в число акторов международной системы индивидов, транснациональных корпораций и других частных субъектов, исходил и американский юристмеждународник Ф. Джессоп, выдвинувший теорию транснационального права. Под последним он понимал всю совокупность правовых норм, регулирующих действия или события, выходящие за пределы государств, включая нормы как международного публичного, так и частного права ${ }^{28}$. Международное сообщество Ф. Джессоп представлял в виде системы множества разнородных субъектов (индивидов,

${ }^{26} \mathrm{Cм.:} \mathrm{Тункин} \mathrm{Г.И.} \mathrm{Указ.} \mathrm{соч.} \mathrm{С.} \mathrm{12-22.}$

${ }^{27} \mathrm{CM}$ : : Burley Anne-Marie. Law Among Liberal States: Liberal Internationalism and the Act of State Doctrine // Columbia Law Review. Vol. 92. 1992. P. 1920-1921.

${ }^{28}$ Jessup Ph. Transnational Law. New Haven, 1956. P. 2 ff. 
корпораций, государств), взаимодействующих через национальные границы.

Транснациональные взгляды Ф. Джессопа получили широкое распространение в зарубежной правовой доктрине. На них, в частности, опирались сторонники теории «юридического плюрализма», обосновывавшие положение о том, что в одно и то же время, на одном и том же социальном пространстве могут сосуществовать несколько правовых систем, как государственных, так и независимых от государства ${ }^{29}$. Примером одной из более поздних модификаций концепции Ф. Джессопа может служить теория «транснационального юридического процесса» Г. Коха, в рамках которой он пытался объяснить, как публичные и частные акторы, взаимодействуя на внутригосударственном и международном уровнях, создают, толкуют и осуществляют нормы транснационального права ${ }^{30}$.

В заключение краткого обзора зарубежных концепций международной системы второй половины ХX века хотелось бы отметить, что в данном случае мы имеем дело с широким спектром взглядов различных авторов, характеризуюших современное состояние и будущее мирового порядка, от чрезвычайно пессимистичных до неоправданно оптимистичных. Нетрудно догадаться, что заметное влияние на содержание указанных концепций оказывала не только принадлежность их разработчиков к тем или иным правовым школам (естественной, позитивистской, социологической и др.), но и состояние «холодной войны», существовавшее в то время в отношениях между капиталистическими и социалистическими государствами, а также приверженность авторов соответствующих теорий определенным политическим идеям и ценностям. Поэтому очевидный недостаток многих из приведенных выше точек зрения состоит в субъективном, «выборочном» взгляде их авторов на окружающую действительность, в отсутствии объективной оценки динамики развития международных отношений, а таюже роли международного права в процессе их регулирования.

Конечно, международная система была, да и сегодня еще во многом остается децентрализованной и слабо интегрированной структурой, что объективно работает в пользу силовых акций. В то же время нельзя не отметить и тот факт, что международное сообщество неуклонно развивается в направлении все большей интегрированности его субъек-

${ }^{29}$ См.: Eвинтов В.И. Указ. соч. С. 34.

${ }^{30}$ Cм.: Koh H. Transnational Legal Process // Nebraska Law Review. Vol. 75. 1996. P. 183-184. 
тов, что создает объективные предпосылки для нарастающего влияния не силовых, в том числе правовых, факторов ${ }^{31}$. Несмотря на непрекращающиеся региональные конфликты и наличие целого ряда других негативных факторов, современный мир полон примеров, подтверждающих неуклонное движение человечества по пути к более устойчивому и целостному международному сообществу.

Интенсификация глобализационных процессов, особенно явственно проявившаяся на рубеже XX и XXI веков, не могла не оказать влияния на дальнейшее развитие учения о правовой системе в рамках как общей теории права, так и международно-правовой доктрины. Именно поэтому отличительной чертой многих разработок и зарубежных ученых последних лет является более продуманное и взвешенное отношение к понятию и содержанию терминов «правовая система государства» и «международно-правовая система».

Oпределяющее влияние на содержание их концепций, как и в нашей стране, оказали новые тенденции мирового общественного развития, которые привели к распаду сложившейся после Второй мировой войны системы международных отношений, основанной на противостоянии блоков социалистических и капиталистических государств. На смену биполярному миру времен холодной войны пришла динамично развивающаяся новая сложная мировая система, характеризующаяся многополярностью и многомерностью всех составляющих ее компонентов. Указанные изменения возродили надежды многих зарубежных политических и научных деятелей на существенное сближение Востока и Запада и, как следствие, построение единого мирового сообщества, основанного на универсальных ценностях, принципах взаимопомощи и сотрудничества всех государств мира.

Так, например, немецкий профессор Дж. Делбрук, определяя международную систему прежде всего как систему межгосударственных отношений, а таюже отношений, возникающих между отдельными странами и международным сообществом в целом, отмечает, что сегодня «мы можем наблюдать новые направления сотрудничества между государствами, которые раньше находились в оппозиции друг к другу или держались друг от друга на расстоянии. Как следствие, новый импульс получила деятельность международных организаций универсального и регионального характера и, в особенности, Организации

${ }^{3 \prime}$ См.: Генов $И$. Соотношение права и силы в международных отношениях // Советское государство и право. 1987. № 6. С. 95. 
Объединенных Наций. Их укрепление, наряду с развитием других направлений институционального сотрудничества, в настоящее время признается ключевой предпосылкой достижения новой стабильности в пределах международной системы».

Дж. Делбрук специально подчеркивает необходимость «нового осознания важности международного права как юридического каркаса всеобъемлющего и стабильного мирового порядка» ${ }^{32}$. Однако повышение эффективности международного права в современном мире, по мнению немецкого профессора, не дает оснований для отношения к нему как к мировому или глобальному праву. «Несовершенство механизма осушествления международно-правовых норм и все еще сохраняющая свое значение парадигма государственного суверенитета, - пишет Дж. Делбрук, - не позволяют говорить о возможности изменения межгосударственной природы международного права» ${ }^{33}$.

Вместе с тем, по мнению подавляющего большинства зарубежных авторов, к современному международному праву уже нельзя относиться и как к нормативной конструкции, предназначенной для регулирования исключительно межгосударственных отношений, выходящих за рамки национальных границ. «В XX веке, - отмечает американский профессор Д. Бедерман, - государства перестали быть единственными субъектами международно-правовых норм. Это, несомненно, стало одним из наиболее существенных изменений в этой области права, сделав возможным применение его норм в отношении широкого круга индивидов, учреждений и коммерческих предприятий» ${ }^{34}$. Профессор университета г. Питтсбурга Р. Бранд также согласен с тем, что в прошедшем веке получили развитие «прямые связи между индивидом и международным правом». По его мнению, сегодня «международное право в некоторых случаях обращается непосредственно к индивидам. Государство по-прежнему остается органом, представляющим их интересы в процессе развития международных норм и механизмов, но оно уже не всегда может вмешиваться в ситуацию в тех случаях, когда такие нормы применяются, а механизмы осуществляются) ${ }^{35}$.

${ }^{32}$ См.: Delbruck J. A More Effective International Law or a New "World Law»? Some Aspects of the Development of International Law in a Changing International System // Indiana Law Joumal. Vol. 68. 1993. P. 705-706.

${ }^{33}$ Ibid. P. 725.

${ }^{34}$ Bederman D.J. International Law Frameworks. New York, 2001. P. 1.

${ }^{35}$ Brand R.A. External Sovereignty and Intemational Law // Fordham International Law Journal. Vol. 18. 1995. P. 1695-1696. 
Как уже указывалось, в качестве одного из характерных признаков «нового международного права» в западной правовой доктрине часто называют увеличение роли и значения международных организаций в процессе регулирования отношений между государствами, а также при осуществлении контроля за их деятельностью. Некоторые зарубежные исследователи считают даже, что сегодня следует говорить о смещении полномочий по созданию, толкованию и приведению в исполнение норм международного права от национальных правительств к международным организациям ${ }^{36}$.

Довольно интересную точку зрения на этот счет высказывает итальянский профессор У. Маттеи. Характеризуя существо процесса эволюции современного международного права, он отмечает, что в настоящее время и в теории, и на практике наблюдается отход от его традиционного понимания как децентрализованной системы правовых норм, основанной на территориальном верховенстве и незыблемости государственного суверенитета. По мнению У. Маттеи, международное право приобретает черты все более централизованной структуры, что постепенно сближает его с национальными правовыми системами отдельных стран. «Сегодня считается, - указывает он, - что международное право представляет собой совокупность позитивных норм, основными источниками которого являются договоры и обычаи. Завтра мы, скорее всего, будем полагать, что международное право - это всемирная правовая система, основанная на однородных и повсеместно разделяемых идеалах правопорядка». Первые шаги на пути формирования этой обновленной международной централизованной правовой системы, по мнению У. Маттеи, уже были сделаны в процессе учреждения целого ряда новых международных кодексов, судов и даже международных тюрем, которые к сегодняшнему дню получили широкое признание на мировой арене ${ }^{37}$.

При этом У. Маттеи совершенно уверен, что международное право, как, впрочем, и национальные правовые системы в будущем будет находиться под усиливаюшимся год от года воздействием правовой доктрины и юридических институтов США, что приведет в конечном итоге к формированию некоего «имперского права», основанного на стандартах и ценностях американской юриспруденции. «Существо современного этапа развития глобального юридического сознания, - подчеркивает он, - заключается в его повсеместной американизации» ${ }^{38}$.

${ }^{36} \mathrm{Cm}$., например: $K u$ J.G. The Delegation of Federal Power to International Organizations: New Problems with Old Solutions // Minnesota Law Review. Vol. 85. 2000. P. 87-88.

${ }^{37}$ См.: Mattei U. A Theory of Imperial Law: A Study on U.S. Hegemony and the Latin Resistance // Indiana Journal of Global Legal Studies. Vol. 10. 2003. P. 400.

${ }^{38}$ Mattei U. Op. cit. P. 442. 
Рассматривая содержание современных теоретических взглядов на природу и сущность международного права, нельзя не отметить и тот факт, что в зарубежной правовой доктрине в последние годы определенное развитие получили концепции, пытающиеся поставить под сомнение саму юридическую природу международно-правовых норм и доказать необходимость изменения понятия международного права. Так, например, американский профессор Э. Гузман считает, что к современному международному праву, помимо традиционных договорных и обычных источников, следует относить любые обещания или решения, которые способны оказывать побудительное воздействие на поведение государства материального или репутационного характера ${ }^{39}$. Поэтому, по мнению Э. Гузмана, понятие международного права должно приобрести функциональную окраску и отражать существо процесса воздействия подобных обещаний и решений на мотивацию внешнеполитических шагов различных государств мира ${ }^{40}$.

Однако болышинство зарубежных исследователей все же не считают возможным объединять как правовые, так и неправовые регуляторы общественных отношений «под вывеской» международного права, признавая существование в рамках международной системы не только юридических, но и других международных нормативных конструкций. «Право не является единственным путем, при помощи которого отношения, выходящие за рамки национальных границ, приводятся в порядок, - указывает, например, английский юрист-международник M. IIIoy. - Это лишь один из методов воздействия на сложную и изменчивую систему таких отношений, престиж и влияние которого основаны на взаимном принятии на себя субъектами права определенных обязательств. Право и политика не должны разделяться. Они пребывают в постоянном тесном взаимодействии. Ни одна из этих дисциплин не может принизить значение другой ${ }^{41}$.

Наметившаяся в зарубежной правовой доктрине эволюция взглядов на субъектные и предметные характеристики международного права и его роль в современных международных отношениях не могла не отразиться и на представлениях западных ученых о параметрах международной системы, нормативной подсистемой которой, как извест-

\footnotetext{
${ }^{39}$ Cм.: Guzman A.T. A Compliance-Based Theory of International Law // California Law Review. Vol. 90. 2002. P. 1825.

${ }^{40}$ Ibid. P. 1881-1883.

${ }^{41}$ Shaw M.N. International Law. Third Edition. Cambridge. 1991. P. 57.
} 
но, является международное право. Сегодня многие из них считают, что к числу субъектов этой системы, помимо государств и межгосударственных образований, должны быть безусловно отнесены также индивиды и негосударственные структуры, отношения с участием которых регулируются международно-правовыми нормами. «Совершенно ясно, - подчеркивает все тот же М. Шоу, - что современное международное право функционирует в особенной, конкретной мировой системе, включающей целый ряд акторов от государств до международных организаций, компаний и индивидов, и, следовательно, оно ответственно перед нуждами и стремлениями таких субъектов) ${ }^{42}$.

С расширением сферы действия международного права и постепенным упрочением институционного каркаса органов, обеспечивающих осуществление на практике положений его норм, в зарубежной правовой доктрине все большее признание получает мысль о принципиальном сходстве международной и внутригосударственных правовых систем. Как указывает американский исследователь У. Асевес, «международная система в определенном смысле является отражением внутригосударственного общества; ее нормы, правила и институционные структуры отличны по форме, но не по существу ${ }^{43}$.

На этом фоне в западных политических и правовых школах произошло значительное сокращение числа сторонников «реалистических» концепций международной системы, основанных, как было показано выше, на тезисе об анархии международного сообщества и принципиальной невозможности совпадения интересов различных государств мира. Целый ряд зарубежных авторов считают сегодня, что эти теории «не в состоянии отобразить новые особенности глобального общества, включая увеличивающуюся живучесть норм международного права и международных институционных структур ${ }^{44}$.

С сокращением влияния «реалистической» школы в зарубежной правовой доктрине существенно возросло значение других юридических концепций, оспаривающих справедливость и легитимность построения современной международной системы. В их числе среди наиболее известных можно, в частности, назвать «критическую теорию юридического образования», «критическую расовую теорию», «тео-

${ }^{42}$ Ibid.

${ }^{43}$ Aceves W.J. Critical Jurisprudence and Intemational Legal Scholarship: A Study of Equitable Distribution // Columbia Journal of Transnational Law. Vol. 39. 2001. P. 316.

${ }^{44}$ Spiro P.J. Globalization, International Law, and the Academy // New York University Journal of International Law and Politics. Vol. 32. 2000. P. 582. 
рию критического феминизма» и теорию «LatCrit» ${ }^{45}$. При всех разногласиях, существующих между этими концепциями, их приверженцы сходятся на мысли о том, что нормы, правила и институты современной международной системы социально сконструированы, созданы и охраняются не международным сообществом в целом, а определенными доминантными группами (расовыми, культурными, политическими, экономическими, интеллектуальными), функционирующими в его рамках. Поэтому, на их взгляд, эти нормы, правила и институты не могут в одинаковой степени отражать и защищать интересы всех субъектов международной системы и, следовательно, должны быть пересмотрены.

Завершая краткий исторический обзор развития концепции правовой системы в зарубежной правовой доктрине и отнюдь не претендуя на его полноту и всесторонность, хотелось бы обратиться к мысли А.М. Васильева. Еще 20 лет назад он подчеркивал, что термин «правовая система» не отменяет других юридических терминов, не является их синонимом, а несет самостоятельную научную нагрузку, обозначая понятие, синтезирующее на новом уровне наши взгляды обо всех правовых структурах жизни ${ }^{46}$.

Родовое единство международного и внутригосударственного права как совокупности общеобязательных правил поведения юридического характера дает основание утверждать, что первое, как и второе, лежит в основе своей собственной правовой системы, находящейся в постоянном тесном взаимодействии с правовыми системами отдельных государств. Только речь в данном случае идет не о национальной, а о международной правовой системе, обладающей определенной спецификой.

Эта специфика, в частности, заключается в том, что если социальная среда национальной правовой системы ограничивается рамками конкретной страны, то в случае с международной правовой системой речь в этом отношении должна идти о категории «мировое сообщество», охватывающей значительно более широкий круг субъектов - от государств и международных организаций до транснациональных корпораций и индивидов, являющихся участниками отношений, выходящих за рамки национальных границ. Каждый из указанных субъектов вно-

${ }^{45}$ Подробнее о содержании этих концепций см., например: Aceves W.J. Op. cit. P. 309324; Román E. A Race Approach to Intemational Law (Rail): Is There a Need for Yet Another Critique of Intemational Law? // U.C. Davis Law Review. Vol. 33. 2000. P. 1519-1545.

${ }^{46}$ См.: Васильев A.M. О системах советского и международного права // Советское государство и право. 1985. № 1. С. 66. 
сит свой вклад в обеспечение нормального сушествования и развития мирового сообщества. Тем не менее функции его управляющей подсистемы во всех случаях непосредственно или опосредованно выполняет международное сообщество государств ${ }^{47}$.

Именно государства обладают правомочиями устанавливать в рамках мирового сообщества по согласованию друг с другом юридически обязательные правила поведения, формировать его институционный каркас, а также определять перечень и компетенцию других субъектов, выполняющих подобные функции. Создаваемые при этом на универсальном, региональном или двустороннем уровне нормативно-правовые предписания (при достижении между государствами соответствующей степени согласия) распространяют свое обязывающее или управомочивающее действие на все субъекты мирового сообщества.

${ }^{47}$ См.: Лукащук И.И. Глобализация, государство, право, XXI век. М., 2000. С. 60-6I, 112. 